\title{
TID/SNA -198
}

\section{VON KARMAN CENTER}

LIFE SUPPORT SYSTEMS DIVISION

A STUDY TO DEVELOP A TOXIC MATERIALS CONTROL

PROGRAM FOR THE APPOLLO EXTENSION SYSTEMS (AES) PROGRAM

A Proposal to

NATIONAL AERONAUTICS AND SPACE ADMINISTRATION

Proposal LS-65402 / July 1965 / Copy No. /

\section{FIL $609 \%$ \\ NoO}

AEROJET

GENERAL TIRE

GENERAL

TECHNICAL DOCUMENT CENTER Nuclear Rocket Operations

Doc. No. $N-0338$ 


\section{DISCLAIMER}

This report was prepared as an account of work sponsored by an agency of the United States Government. Neither the United States Government nor any agency Thereof, nor any of their employees, makes any warranty, express or implied, or assumes any legal liability or responsibility for the accuracy, completeness, or usefulness of any information, apparatus, product, or process disclosed, or represents that its use would not infringe privately owned rights. Reference herein to any specific commercial product, process, or service by trade name, trademark, manufacturer, or otherwise does not necessarily constitute or imply its endorsement, recommendation, or favoring by the United States Government or any agency thereof. The views and opinions of authors expressed herein do not necessarily state or reflect those of the United States Government or any agency thereof. 


\section{DISCLAIMER}

Portions of this document may be illegible in electronic image products. Images are produced from the best available original document. 
NOTICE

This report was prepared as an account of work sponsored by the United States Government. Neither the United States nor the United States Energy Research and Development Administration, nor any of their employees, nor any of their contractors, subcontractors, or their employees, makes any warranty, express or implied, or assumes any legal liability or responsibility for the accuracy, completeness or usefulness of any information, apparatus, product or process disclosed, or represents that its use would not infringe privately owned rights.

\section{AEROJET}

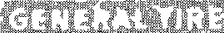

GENERAL

12.

A STUDY TO DEVELOP

A TOXIC MATERIALS CONTROL PROGRAM

FOR THE APOLLO EXTENSION SYSTEMS (AES) PROGRAM

A Proposal to

NATIONAL AERONAUTICS AND SPACE ADMINISTRATION

Proposal No. LS-65402

July 1965

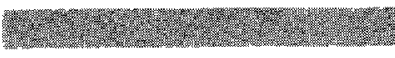

- 
This document and the data furnished herein or herewith shall not be disclosed outside the recipient organization or the Government, or be reproduced, used or disclosed in whole or in part for any purpose other than evaluation of this proposal by the recipient organization and/or $:$ the Government; provided that if a contract is awarded to AerojetGeneral Corporation as the result of or in connection with the submission of such data, the Government shall have the right to reproduce, use or disclose this data to the extent provided in the contract. 
I. INTRODUCTION AND SUMMARY

II. PROGRAM REQUIREMENTS

2

III. CONTENT OF THE PROPOSED STUDY

5

IV. TECHNICAL APPROACH

General Considerations

A. Determination of Specifications and Materials Tests

8

1. Definition of "Safe Air"

8

2. Determination of Specification and Test Criteria

3. Determination of Test Procedures 12

4. Determination of Test Choice and Sequencing 16

5. Development of Test Schedules 17

B. Data Storage and Retrieval 17

1. Data-Poo1 Requirements and Constraints 18

2. Data-Pool Design and Development 19

C. Project and Program Management 23

1. Definition of AES Project Organization 23

2. Definition of AES Development Cycle 24

3. Determination of Capabilities of Participating Organizations

4. Determination of Preliminary-Configuration Management Recommendations

D. Assignment of Responsibility for Specifications, Tests, and Data-Pool Functions

E. Finalization of TMCP Design

1. Definition of Material-Selection Specifications and Management Control Program 30 


\section{CONTENTS (cont.)}

$\underline{\text { Page }}$

2. Establishment of Management Responsibility and Organization

3. Preparation of Final Report

V. STUDY PROGRAM PLAN

VI. CAPABILITIES

A. Applicable Experience 35

B. Facilities 38

- 1. Life Support Sys tems Division 38

2. Chemical Structural Products Division 41

3. Corporate Technical Library 42

4. Computing Sciences Division 44

C. Organization and Personnel 44

1. Key Personnal 45

2. Consultants 49

FIGURE 1 - Study Program Plan 50

TABLE 1 - List of Known Closed-Sys tem Contaminants 13 
I. INTRODUCTION AND SUMMARY

Atmospheric contamination in manned spacecraft has been under extensive investigation by the Life Support Systems Division of Aerojet-General Corporation. Trace contaminants will be contributed by materials of construction and the crew, and toxicological information on continuous exposure to low concentrations of a variety of contaminants is notably lacking.

Predictions on the safety and reliability of various space missions must nevertheless be made, and a continuously breathable atmosphere: in the cabin will be a vital factor. Because it is a foregone conclusion that.extended missions will be flown, efforts must be made to control atmospheric contamination to safe limits that will contribute to mission success.

Contamination can be controlled effectively by controlling the materials and equipment used in the habitable portion of the spacecraft. This can be done for the Apollo Extended Systems (AES) Program with the aid of a materials-selection specification based on (a) knowledge of the candidate materials and equipment, and (b) the setting of reliable and biologically significant limits. This specification will require implementation, monitoring, and administrative integration with the AES Program and NASA schedules.

We propose, on the basis of our studies of the problem, a short-term, broadly based program to develop (a) a specification for inclusion in pertinent AES contracts to govern the selection of materials and equipment, (b) organization and management recommendations for a Toxic Materials Control Program (TMCP), and (c) descriptions of research and development programs that may be needed for the control of toxic materials.

An experienced team of Aerojet engineers and scientists under the direction of $\mathrm{Dr}$. M. Y. Longley has been investigating significant aspects of this program intensively for the past 2 years, and is believed to be uniquely qualified to conduct the proposed work successfully, expeditiously, and economically. 
II. PROGRAM REQUTREMENTS

A safe atmosphere in spacecraft interiors becomes a prime requisite for mission success whenever men are aboard. In the closed spacecraft environment, when leakage is minimized and the atmosphere is continuously. recirculated, gradual contamination by accumulated toxic gases, vapors, and particulates emitted by the crew, materials, and equipment must be expected even under normal operating conditions. This atmospheric contamination is time-dependent; as mission durations increase, contaminant concentrations will also increase. The possibility of equipment failures, fires, and other emergency conditions increase the probability of reaching concentrations that can be detrimental to the $\mathrm{crew}^{2} \mathrm{~s}$ performance, comfort, and wellbeing. The reality of the contamination problem in enclosed atmospheres has been demonstrated by the difficulties encountered in jet aircraft, submarines, and ground-based space-cabin simulators.

To minimize the probability of an aborted mission (due to out-oftolerance astronaut performance or health), on-board atmosphere-purification systems for the removal of trace contaminants will be incorporated. The cost of such ontboard contaminant-removal equipment in terms of weight, power, and volume must be minimized while system reliability is maximized. An additional highly desirable requirement, particularly from the engineering and manufacturing points of view, is to avoid exceeding the state of the art of trace-contaminant-removal equipment.

These requirements for assuring a reliable and safe atmosphere for the spacecraft crew may be fulfilled by initiating a Toxic Materials Control Program (TMCP) during the spacecraft development cycle. Such a program would be designed to effect the controlled selection of spacecraft materials and equipment based on toxicological considerations, and thus to control trace contaminants introduced into the spacecraft atmosphere. Potentially, it would result in

A. A minimum load on the on-board contaminant-removal system, 
with consequent reduction in cost in terms of weight, power, and volume

B. A maximum reliability of the on-board removal system by providing for (1) increased permissible down time of the on-board removal system for maintenance or repair, and (2) a margin of safety between the capacity of the on-board removal system and the contaminant-production rate

C. Avoiding pushing the limits of the state of the art by elimination of contaminants that would require on-board removal equipment beyond existing design knowledge and capacity.

D. Detailed information regarding the design requirements and performance capability of the on-board contaminant-removal system.

In general, a toxic-materials control process may be represented schematically as shown below:

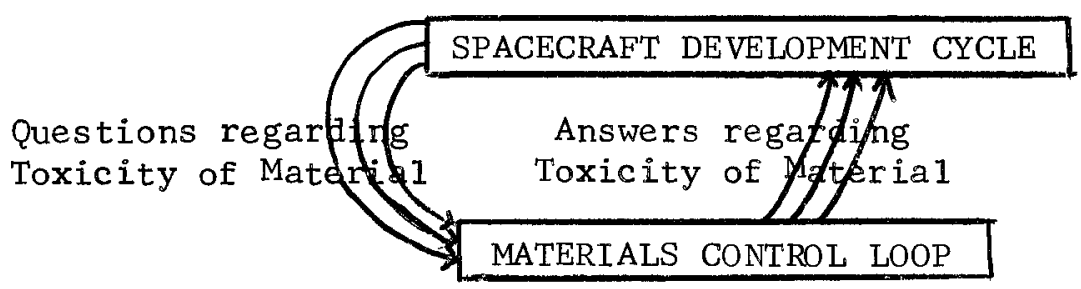

The materials control process is seen as a loop in parallel with the spacecraft development cycle. Pertinent basic information on candidate materials and equipment to be used inside the spacecraft is supplied to this loop by spacecraft systems engineers. The material and equipment are then considered with regard to toxicology. Those with potential for contributing significant contaminant loading to the enclosed atmosphere are identified, and consideration is given to arguments for and against these materials. This process will sometimes lead to substituting alternative noncontaminating materials and processes and thus to a reduction in the total contaminant loading. At other times, it will not be possible to find alternative noncontaminating materials and processes. Even in such cases, however, there will be a gain as a result of the evaluation; the loading that will be placed upon the on-board contaminant-removal system will be specified. 
The TMCP thus involves (a) identifying candidate materials, equipment, and processes for use in the space cabin, (b) toxicological evaluation, and (c) determination to reject or control contaminating materials or, alternatively, to place a specified burden on the contaminant-removal system.

The general requirement for a TMCP is thus readily apparent. Before electing to implement such a program, however, it must be demonstrated that the program will actually be worth its cost. Although a specified design for a TMCP may be justifiable in terms of general requirements, it may not be worth its cost in terms of the maximum effect it can achieve. If a TMCP has a potential for meeting the requirements outlined above, there is thus a need to determine whether a specific implementation method can be developed whose effectiveness will be commensurate with its costs. Cost effectiveness data for alternative program designs are also required to provide a basis for selection of the optimum program.

Aerojet, therefore recommends as a first step, in view of the obvious need for some form of control of potentially toxic space-cabin materials, that a broadly based study be undertaken to design a program and determine means for implementing it. The discussion that follows outlines the major outputs of the proposed study. 
To implement the most fully effective TMCP, research and development work on new techniques and facilities would be needed. This would require time that is not available before the Apollo Extension Systems (AES) enter the early design phases. Aerojet therefore proposes (a) to develop a TMCP within the present state of the art that is applicable to the AES, (b) to supply NASA the technical and management data needed to implement this TMCP, and (c) to identify the research and development work that should be undertaken for possible TMCP upgrading at a later date.

It is possible, however, that a TMCP restricted to state-of-the-art approaches may not be sufficiently effective to justify the associated cost. Consequently, information on the cost effectiveness of the TMCP that can be implemented now will be provided to permit the NASA to decide whether that program is justified in terms of funds, manpower, facilities, and time.

The proposed study will yield a TMCP design in sufficient detail to allow the decisions necessary for program initiation. If the proposed TMCP design is accepted by the NASA, further work will of course be required to inaugurate it.

Aerojet proposes to develop and report the following specific data:

A. Description of a TMCP in terms of its major technical functions and management tasks, their outputs, and the interrelations among these functions and tasks (including details on the relationship between the TMCP and the AES development cycle).

B. A recommended management concept that includes definition and allocation of responsibilities, a description of the organization necessary to effectively ensure adequate control of material selection, and integration with the AES Project 
C. Estimates of TMCP costs in terms of funds, personne1, facilities, schedules, and other factors pertinent to the overall AEs, thus permitting a cost-effectiveness approach to TMCP implementation in its final form

D. A detailed material-selection specification, (fully compatible with the foregoing management program? for the control of potentially toxic materials, that may be included in AES work statements for prime contractors, subcontractors, vendors, and suppliers

E. Description of research and/or facilities needed in areas where fully satisfactory means for determining the pertinent characteristics and biological effects are not available.

These outputs will be developed as described on succeeding pages. 
IV. TECHNICAL APPROACH

GENERAL CONSIDERATIONS

Aerojet's approach to the end products outlined above is planned in five basic areas, which are subdivided into discrete steps that contribute outputs in building-block.fashion.

Program interrelationships, data flow, and scheduling are depicted in Figure 1 (which follows the text). The task descriptors correspond to specific elements of this discussion. They may be grouped as follows: determination of specifications and tests (Tasks 1 through 5), design of data pool (Tasks 6 and 7), project and TMCP management definition (Tasks 8 through 11), assignment of technical responsibilities (Task 12), and final TMCP design (Tasks 13 through 15). Scheduling and timing are in Section V. Several key terms used in this proposal are defined below.

"Materials" may be considered to occur in the form of solids, liquids, or gases. Either as they appear in the space cabin or as tested, they may take the form of isolated objects, pieces of equipment or machinery, or even complete subsystems. Compounds and elements that might issue from various materials and contaminate the atmosphere will generally be referred to as "contaminants".

"Work statement" is used in the same sense as it appears in the schedule portion of a contract. It outlines, for the complete contract, the items of work to be accomplished in order to fulfill all contract obligations.

"Specification" is used in its standard engineering connotation. It details, in very specific fashion, the requirements that have to be met in the design, fabrication, and testing of. an end product, 
or of the components of that end product. Specifications may appear in the work-statement section of a contract schedule and/or as part of the special-provisions section.

\author{
"Test" is used to designate a means for checking adherence \\ to specification requirements. A test would have as one of its elements \\ a series of procedures.
}

These definitions are compatible with discussions in the NASA Configuration Management Manual (No. NPC 500-1, 18 May 1964), which covers the management of technical requirements that define systems, sys tem equipment, and changes thereto. "Configuration Management" is implemented through procedures by which uniform and mutually supporting methods for configuration identification, control, and accounting are established and maintained for systems and equipment and for components of systems and equipment. The method of implementation is derived from the concept of base-1ine management. Base lines may be established at any point where it is necessary to define a formal departure point for control of future changes in performance and design. These base lines are documented by approved specifications, which provide the basis for control of future changes in system performance and design. An elemental reason for defining the system in terms of specified requirements is to provide a tangible basis for determining contract costs and incentives. Essentially, system program management is change management. Properly applied, configuration management is the keystone for correlating total program costs and schedules with approved equipment requirements.

A DETERMINATION OF SPECIFICATIONS AND MATERIALS TESTS

\title{
1. Definition of "Safe Air"
}

The specifications and test procedures that will eventually be written require the establishment of certain standards and limits. These limits, although they are difficult to set and inherently controversial must be decided upon early in the program. "Safe air" 
will be defined on the basis of (a) data and opinions gathered from recognized authorities in space medicine and toxicology, and (b) knowledge of all pertinent details about the specific mission involved.

Generally, safe air is an atmosphere that must contain oxygen and be "clean." Oxygen provisioning is relatively straightforward; the provisioning of clean air is not. The problem derives from the difficulty in developing a comprehensive and objective engineering definiton of clean air. Man himself will be the source of many unavoidable contaminants, and many more will be contributed by materials and equipment in the cabin. The great number of potential contaminant compounds makes it a formidable task to draft a specification for clean air that lists all possible contaminants and the maximum safe concentrations permissible for each. A preliminary definition of safe air in terms of the upper limits of allowable concentrations is required, however, in order to establish design specifications for on-board air-purification systems (APSs) and contaminant-monitoring equipment.

A reliable, safe atmosphere is dependent upon (a) contaminant removal by an APS, and (b) a set of functions that will evaluate and limit the quantity and diversity of contaminants at their sources. Contaminant removal is required because spacecraft+atmosphere contamination by the crew, materials, and equipment cannot be avoided under normal as well as emergency conditions. The second set of functions is essential in order to assure that (a) no toxic conditions will exist in the spacecraft cabin due to the presence of materials that outgas during normal operation, and (b) sufficient margin is provided between APS capacity and the actual input to the APS. With such assurance, the probability of mission success would be considerably increased.

Certain data, but not all, are available on materials that were used in the Mercury cabin, will be used in Apollo, and have been used in other closed-atmosphere environments. Work can therefore be initiated immediately in an effort to develop a list of (a) approved, (b) questionable, and (c) unacceptable fabrication materials. These materials can, 
moreover, be placed in functional groups for examination with regard to their probable toxicological effects. It should, in fact, be possible to list the majority of materials that may be considered for AES.

As part of a company-funded program, Aerojet has undertaken the identification of trace contaminants (and their sources) most likely to be found in spacecraft atmospheres. A list of 100 trace contaminants most likely to be presented in spacecraft atmospheres was prepared on the basis of substances identified or suspected in submarines, spacecraft, and spacecraft simulators and test chambers, and their probable sources were identified by deductive chemical reasoning (see Table 1).

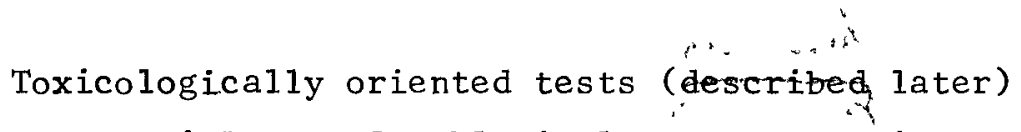
can be applied to these materials, preferably in large groups, in an effort to provide the designer with a list for use in material selection that will result in a configuration with a high probability of being safe. This effort will also materially facilitate at least a crude estimation of the total quantities of specific compounds emanating from all cabin materials. Such an engineering-design document can decrease the amount of work necessary under the proposed control program, because only the new or unique materials suggested for the cabin will require testing.

Many factors associated with the AES mission must be known before a realistic set of standards or limits can be devised. In addition to the length of mission, cabin volume, leakage rate and similar data, it is necessary also to have information on other less apparent factors such as planned venting of the cabin to space, crew work-rest cycles, and personal-hygiene operations. These factors and others contribute to both the total quantity of the contaminats and the rate at which they build up. During this study, as in any sort of materials control program, changes in these parameters must be made known to the investigators. The APS is one of the most important subsystems with regard to contaminant control. Its characteristics must be known in great detail, and any 
changes in it may affect the choice or rejection of a large number of materials.

The outputs of the efforts discussed here will be (a) a definition of safe air in terms of the maximum allowable contaminant concentrations in the habitable areas of the spacecraft, (b) an estimate of the performance characteristics of the presently projected on-board contaminantremoval system in terms of the resulting contaminant concentrations as a function of contaminant-production rate, and (c) estimates of the weight, power, and volume costs of the presently projected on-board system.

The safe-air definition will be based on atmospheric requirements for unimpaired physical and psychological performance of the crew. The maximum allowable concentrations of trace contaminants will be obtained by making use of extrapolation techniques now under development by Aerojet, and others, which attempt to convert conventional exposure data to predictions of the toxicity of outgassing compounds in the spacecraft environment during continuous long-duration exposure. The extrapolation will consist essentially of determining the susceptibility of various species of laboratory animals to varieties of toxic substances and (using experimentally determined conversion factors) assigning maximum-allowableconcentration values for human exposure under spacecraft conditions. In addition, the toxicological literature will be reviewed for recent values determined experimentally in simulators and manned spacecraft.

Information thus obtained will contribute to a toxicological data pool and form a basis for an engineering-guidance document. The limits on many pure compounds (but not necessarily on fabricated materials) can now be set with some confidence. This information would be useful in any type of TMCP, but it is of direct use to the proposed study because it provides the basic elements of a material-selection specification. 
2. Determination of Specification and Test Criteria

Some of the basic elements of specification criteria* are known at this time; once the definition of safe air has been agreed upon, criteria (particularly for testing) can be established. These criteria will then dictate the writing of toxicological specifications and associated test procedures.

Even at this early stage of the work it will be apparent that criteria can be so demanding or complex that there will be no hope for realistic adherence to the program. On the other hand, criteria may be so nonrestrictive that reasonable reliance on their ability to adhere to the definition of safe air is impossible. Many specifications currently used in spacecraft-development cycles fall into one of these categories. A series of trade-off analyses are clearly necessary at this point. The criteria must be realistic but oriented as much as possible toward determinations of known biological (human) effects. This task demands the attention of experienced toxicologists, because the relationships between either chemical analyses or animal experimentation and human toxicity are dubious, and the setting of upper and lower limits is therefore difficult when a consensus among toxicologists is sought. These limits must be set, however, and at this time must be based on state-ofthe-art knowledge rather than extensive experimental work. (Necessary research and development programs may suggest themselves at this stage of the study.)

\section{Determination of Test Procedures}

As the earliest criteria are established, specific test procedures will suggest themselves. Trade-off analysis that maximize reliability and minimize complexity and time requirements must again be performed. The task of accumulating and selecting procedures, and of writing these procedures in detail, is one of the major efforts of the proposed program. It will involve eombinationg from Aerojet's experienced staff of analytical chemists, physicists, and toxicologists, who have already dealt with such problems at both the Von Karman Center

*Basic technical objectives dictating elements of a specification. 


\section{- Possible SPÁcECRAFT Trace Contaminants}

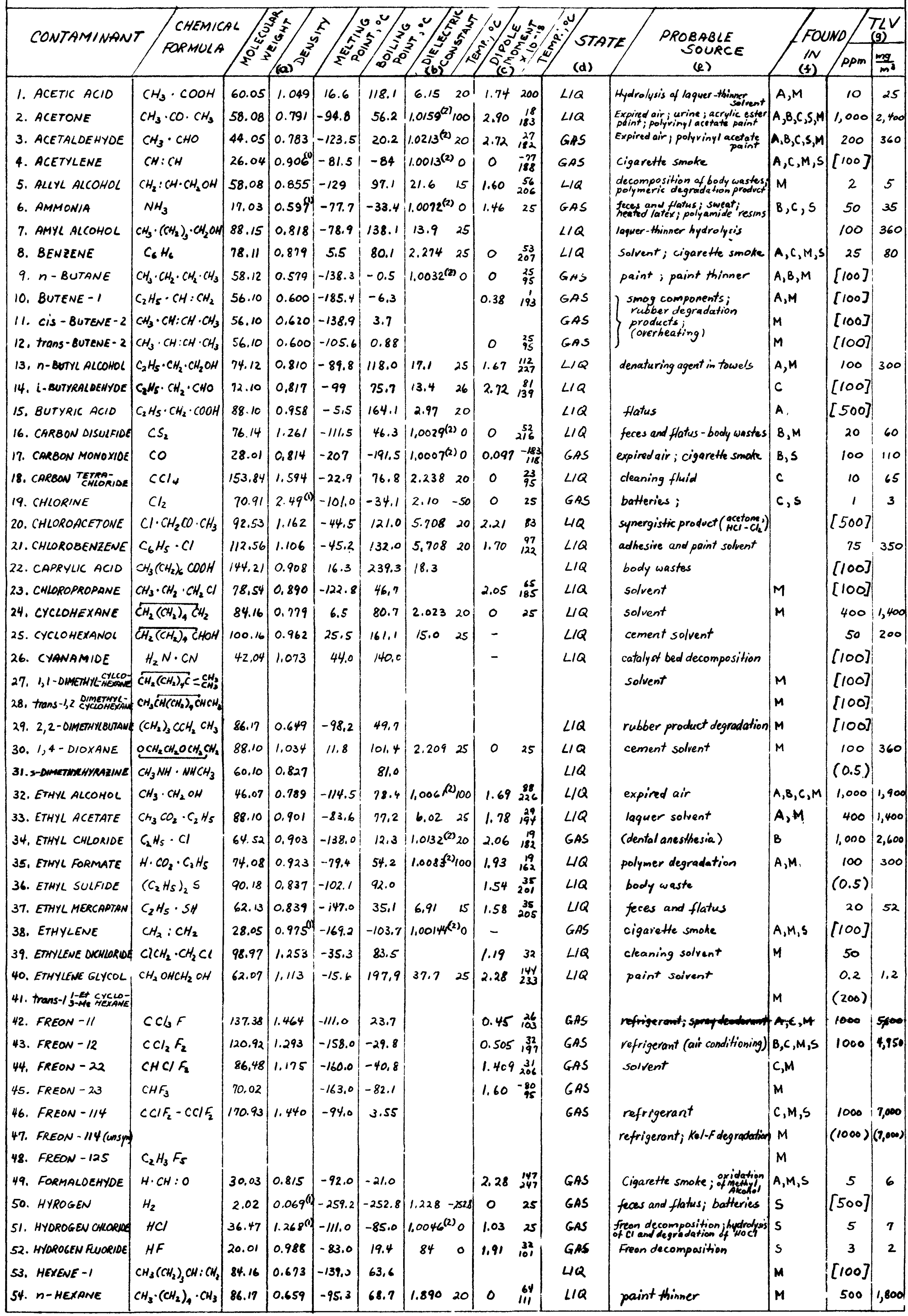




\begin{tabular}{|c|c|c|c|c|c|c|c|c|c|c|c|c|}
\hline & & & & & & & & & (1) & & & $\overline{m^{2}}$ \\
\hline TANE: & {$\left[\left(\mathrm{CH}_{3}\right)_{2} \mathrm{SiO}\right]_{3}$} & 2,5 & & $6 \%, 0$ & 3,0 & & & $5 C L 1 D$ & Silicone greases & $M$ & & \\
\hline 56. HYDROGEN SULFIDE & $\mathrm{H}_{2} \mathrm{~S}$ & 34.08 & $1.189^{\circ}$ & -82.9 & -59.6 & $1.0040^{(3)} 0$ & $\left|\begin{array}{lll}0.92 & -76 \\
269\end{array}\right|$ & GAS & feces and flatus & 5 & 10 & 15 \\
\hline 57. INDOLE & $\mathrm{C}_{6} \mathrm{H}_{4} \mathrm{NHCH}: \mathrm{CH}$ & 117.14 & - & 52.5 & 253.0 & & & SOLID & feces and flatus & & (5) & \\
\hline 58. ISOBUTYL ALCONOL & $\left(\mathrm{CH}_{3}\right)_{2} \mathrm{CH} \cdot \mathrm{CH}_{2} \mathrm{OH}$ & 74.12 & 0.802 & -108.0 & 108.1 & $17.7 \quad 25$ & & $\angle Q$ & solvent & $m$ & 0.5 & \\
\hline 59. ISOPROPYL ALCOHOL & $\left(\mathrm{CH}_{3}\right)_{2} \mathrm{CHOH}$ & $60.09 \mid$ & 0.785 & $\mid-89.5$ & 82.4 & $18.3 \quad 25$ & & $\angle L Q$ & 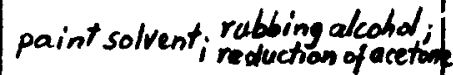 & $M$ & 400 & 1820 \\
\hline O. ISOBUTYLENE & $\left(\mathrm{CH}_{3}\right)_{2} \mathrm{C}: \mathrm{CH}_{2}$ & 56.10 & 0,590 & -140.4 & -6.9 & & & GAS & cigarette smoke & $A, B, S$ & 100 & \\
\hline 1. ISOPRENE & $\mathrm{CH}_{2}: \mathrm{C}\left(\mathrm{CH}_{3}\right) \mathrm{CH}_{\mathrm{CH}} \mid$ & 68.0 & 0.681 & $-146,0$ & $3 h_{1}$ & $2,10 \quad 25$ & $0.38 \quad 204$ & $\angle L Q$ & rubber degradation; expired air & $A, C, S$ & 100 & \\
\hline 62. METHANE & $\mathrm{CH}_{4}$ & 16.04 & $0,554^{4}$ & -182.5 & $-16 / .5$ & $1.00074^{20} 0$ & \begin{tabular}{cc|}
0 & -80 \\
05
\end{tabular} & GAS & feces and flatus; $\mathrm{CO}_{2}$ reduction & $B, 5$ & $1, \infty$ & \\
\hline 63. METHYL ALCOHOL & $\mathrm{CH}_{3} \cdot \mathrm{OH}$ & 32.04 & 0.792 & $-97,8$ & 64.7 & $1.0057 \quad 100$ & $\begin{array}{rr}1.70 & 72 \\
229\end{array} \mid$ & $\angle 1 Q$ & expired air; solvent; woweshe dryss & $B, C, M, S$ & 200 & 2 \\
\hline 64. METHY CHLOROFOEM & $\mathrm{CH}_{3} \cdot \mathrm{CCl}_{3}$ & 133.42 & 1.346 & -32.7 & 74.0 & & $1.449,140$ & $\angle 1 Q$ & solvent for polystyrome (ament) & $M$ & 350 & 1,900 \\
\hline 65. METHIL ETHYC- & $\mathrm{CH}_{3} \mathrm{CO}_{2} \mathrm{C}_{2} \mathrm{H}_{5}$ & 72.10 & 0.805 & -86.9 & 79.6 & & & $\angle L Q$ & paint or cleaning sotvent & $B, C, M, S$ & 200 & 590 \\
\hline $\begin{array}{l}\text { 66. METHYL- 1SOPROPYL } \\
\text { KETONE }\end{array}$ & $\mathrm{CH}_{3} \mathrm{COCH}\left(\mathrm{CH}_{3}\right)_{2}$ & 86.0 & 0.815 & -92.0 & 93,0 & & & $L Q Q$ & drent & $M$ & $(100)$ & \\
\hline 67. METHL MERCAPTAN & $\mathrm{CH}_{3} \cdot \mathrm{SH}$ & 48.10 & 0.896 & -121.0 & 5.96 & & & GAS & feces and flatus & & 10 & 20 \\
\hline 68. METHYLENE CHLORIDE & $\mathrm{CH}_{2} \mathrm{Cl} / 2$ & 84.94 & 1.336 & -96.7 & 40.2 & $1.0065^{(2)} 100$ & $1.54 \quad 24$ & $4 Q$ & & $B, C, M$. & 500 & 1,750 \\
\hline 69. 3-METHYL PENTANE & $\mathrm{CH}_{3} \mathrm{CH}_{2} \mathrm{CHCH}_{3} \mathrm{CH}_{2} \mathrm{O}_{3}$ & 86.17 & 0.676 & & 64,0 & & & $\angle Q Q$ & & $M$. & 100 & \\
\hline 70. MONOMETHYL- & $\mathrm{CH}_{3} \mathrm{NHNH}_{2}$ & 46.07 & & & 87.5 & & & $\angle 1 Q$ & Rooket fuel & & 0.2 & 0. \\
\hline 71. NITRIC OXIDE & No & 30.01 & 1,269 & -163.61 & $|-151.74|$ & & $0.16 \quad 25$ & GAS & burners; smoking & & 25 & \\
\hline 72. NITROGEN DIOXIDE & $\mathrm{NO}_{2}$ & 46.01 & 1.448 & $-11,20$ & 21.15 & & 0.2925 & GAS & burners; smoking & 5 & 5 & 9 \\
\hline 73. NITROGENTETROXIDE & $\mathrm{N}_{2} \mathrm{O}_{4}$ & 46.01 & 1.448 & -11.20 & 21.15 & $2.5^{(0)} 15$ & 0.3725 & GAS & burners; smoking & & 5 & 9 \\
\hline 74. NITROUS OXIDE & $\mathrm{N}_{2} \mathrm{O}$ & 44.02 & 1.226 & -90.83 & -88.48 & $1.00113^{(5)} 0$ & & GAS & anesthetic & $B, 5$. & 100] & \\
\hline 75. OZONE & $\mathrm{O}_{3}$ & 48.00 & 1.658 & 9. -193.0 & -111.9 & & $0.052^{-79} 9$ & GAS & elect. equipment; io & $c, 5$ & 0.1 & 0.2 \\
\hline 76. PHOSGENE & $0: \mathrm{CCl}_{2}$ & 98.92 & 1.371 & -127.9 & 7.6 & & $1.19,30$ & GAS & frean decomposition ; elect.equin & $B, S$ & 0.1 & 0.4 \\
\hline 77. PROPANE & $\mathrm{CH}_{3} \cdot \mathrm{CH}_{2} \cdot \mathrm{CH}_{3}$ & 44.09 & $1,56,10$ & -187.7 & $|-42.17|$ & 1.61 & $0 \begin{array}{l}-46 \\
2 / 3\end{array}$ & GAS & Iding fuels & $M, S$ & 1,000 & 1,800 \\
\hline 78. n-PROPYL ALCOHOL & $\mathrm{CH}_{3} \cdot \mathrm{CH}_{2} \cdot \mathrm{CH}_{2} \mathrm{ON}$ & 60.04 & 0,804 & $-127,0$ & 97,2 & 20.125 & $\left|\begin{array}{ll}1.69 & 103 \\
232\end{array}\right|$ & $\angle 10$ & iction. & $M$ & 400 & 980 \\
\hline 79. n-PROPYL ACETATE & $\mathrm{CH}_{3} \cdot \mathrm{CO}_{2} \cdot \mathrm{CH}_{2} \cdot \mathrm{C}_{2} \mathrm{HS}_{\mathrm{S}}$ & 102.13 & 0.886 & -95.0 & 101.6 & 5.6919 & & 412 & roit products & $A, M$. & 200 & 840 \\
\hline 80. PROPYL MERCAPTAN & $\mathrm{CH}_{3} \cdot \mathrm{CH}_{2} \cdot \mathrm{CH}_{2} \mathrm{SH}$ & 76.15 & 0.836 & -112.0 & 68.0 & & & 42 & nd flatus & & & \\
\hline 8:. PROPYLENE & $\mathrm{CH}_{3} \cdot \mathrm{CH}^{-} \mathrm{CH}_{2}$ & 42.08 & $1.498^{\circ}$ & -185.3 & -47.7 & $1.87 \quad 20$ & $0.35 \begin{array}{r}-37 \\
203\end{array} \mid$ & GAS & wash \& dry towelettes; snoking & $A, B, M, S$ & {$[100]$} & \\
\hline 82. iso-PEntane & $\left(\mathrm{CH}_{3}\right)_{2} \mathrm{CH} \cdot \mathrm{C}_{2} \mathrm{H}_{5}$ & 72.15 & 0.621 & -159.9 & 27.9 & & & $4 Q$ & lighter fluid & $B, M$ & 1.000 & 2,950 \\
\hline 83. $n$ - PENTANE & $\left(\mathrm{C}_{2} \mathrm{H}_{5}\right)_{2} \mathrm{CH}_{2}$ & 72.15 & 0.626 & -129.7 & 36.1 & $1.0025^{(2)} 100$ & 0111 & 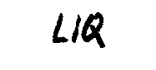 & paint thinmer & $B, M$ & 1,000 & 2,950 \\
\hline 84. PHENOL & $\mathrm{C}_{6} \mathrm{H}_{5} \mathrm{OH}$ & 94.11 & 1.071 & 40.9 & 181.8 & $9.78 \quad 60$ & & $50<10$ & urine; sweat & & 5 & 19 \\
\hline 85. PROPIONIC ACIO & $\mathrm{CH}_{3} \cdot \mathrm{CH}_{2} \cdot \mathrm{COOH}$ & 74.08 & 0.993 & -20.8 & 141.4 & 3.3010 & $1.75 \begin{array}{l}157 \\
213\end{array}$ & $\angle Q$ & feces and flatus & $A$ & {$[100]$} & \\
\hline 86. SKATOLE & $\mathrm{C}_{6} \mathrm{H}_{4} \mathrm{NHCH}: \mathrm{CCH}_{3}$ & 181.17 & & 95.0 & 266.2 & & & SOLID & ind flatus & & & \\
\hline 87. STIBINE & $\mathrm{S}_{6} \mathrm{H}_{3}$ & 124.78 & $4.344^{4}$ & -88.0 & $-17,0$ & & & GAS & batteries & s & 0.1 & 0.5 \\
\hline 88. SULFAR DIOXIDE & $\mathrm{SO}_{2}$ & 64.07 & 2.264 & $-75,5$ & -10.0 & $1.0093^{2} \circ$ & $1.63 \quad-7,17$ & GAS & $\begin{array}{l}\text { urine, oxidation of samitary } \\
\text { tand }\end{array}$ & $C, S, M$. & 5 & 13 \\
\hline 89. TOLUENE & $\mathrm{CH}_{3} \cdot \mathrm{C}_{6} \mathrm{H}_{5}$ & 92.13 & 0.866 & $-95,0$ & 110,6 & $1.0045^{(2)} / 26$ & $\begin{array}{ll}0.36 & 84 \\
209\end{array} \mid$ & $\angle L Q$ & cement or paint solvent & $A, C, M, S$ & $\infty$ & 750 \\
\hline 90. TRICHLOROETHYLENE & $\mathrm{ClCH}: \mathrm{CCl}_{2}$ & 131.40 & 1.466 & -73.0 & 87.2 & $3.4 \quad 16$ & $1.79 \begin{array}{r}28 \\
122\end{array}$ & $\Delta Q$ & cleaning solvent & $A, B, M$ & 100 & 520 \\
\hline $\begin{array}{l}\text { 91. TETRACHLOROETHYIENE) } \\
\text { 92. 1,1,3- TROMETHLV- } \\
\text { CYCLOHEXANE }\end{array}$ & $\mathrm{CCl}_{2}: \mathrm{CCl}_{2}$ & 165.85 & 1.631 & -22.4 & 121.2 & $2.3 \quad 25$ & & $4 Q$ & degreasing solvent & $\begin{array}{l}A, M \\
M\end{array}$ & $\left.\mid \begin{array}{l}100 . \\
{[100]}\end{array}\right]$ & 670 \\
\hline 93. TETRARLURSUETHYLEWE & $C F_{2}: C F_{2}$ & 100.01 & & $-142,5$ & -78.4 & & & GAS & degradation of Tefion & $M$ & & \\
\hline 94. VALERIC ACIDIII) & $\mathrm{C}_{2} \mathrm{H}_{5} \cdot \mathrm{CH}_{2} \cdot \mathrm{CH}_{2} \cos 2$ & $\mid 102.13$ & 0.940 & $\begin{array}{l}-34.5 \\
-59,0\end{array}$ & 186.4 & 2.6620 & & $W Q$ & deoderant & & {$[500]$} & \\
\hline 95. VINYL CHLORIDE & $\mathrm{CH}_{2}: \mathrm{CHCl}$ & 62.50 & 0.905 & $\mid-160,0$ & $-139,0$ & 2.9 & $1.449,140$ & GAS & $\begin{array}{l}\text { decomposition of plastics } \\
\text { and catalyst bed }\end{array}$ & $M$ & 500 & 1,300 \\
\hline 96. VINYLIDENE CHLORDD & $\mathrm{CH}_{2}: \mathrm{CCl}_{2}$ & 96.95 & 1.250 & -122.5 & 37.0 & $3.0 \quad 0$ & $1.90 \begin{array}{r}28 \\
154\end{array}$ & $\angle Q$ & Saran-type plastics & $B, M$ & (506) & $(128)$ \\
\hline 97. $m-X Y L E N E$ & $\mathrm{C}_{6} \mathrm{H}_{4}\left(\mathrm{CH}_{3}\right)_{2}$ & 106.16 & 0.864 & -47.9 & 139.1 & $2.394 \quad 20$ & & $L / Q$ & paint solvent & $M, S$ & 200 & 870 \\
\hline 98. O-XYLENE & $\mathrm{C}_{6} \mathrm{H}_{4}\left(\mathrm{CH}_{3}\right)_{2}$ & 106.16 & 0.880 & $-25,2$ & 144.4 & 2.56820 & $0.62 \begin{array}{c}140 \\
239\end{array}$ & 419 & paint solvent & $M, S$ & 200 & 870 \\
\hline 99. $p$-XYLENE & $\mathrm{C}_{6} \mathrm{H}_{4}\left(\mathrm{CH}_{3}\right)_{2}$ & 106.16 & 0.861 & 13,3 & 138.4 & $2.270 \quad 20$ & 174 & 419 & paint solvent & $M, s$ & 200 & 870 \\
\hline
\end{tabular}

NOTE: (a) The density is given in $\mathrm{g} / \mathrm{ml}$ at $20^{\circ} \mathrm{C}$, except for gases $8 / 1$ at $0^{\circ} \mathrm{C}$ and $760 \mathrm{~mm}$ Hg). The the densily of air $=1,000$.

(b) The dielectric constants for the compounds in The liquid state are for a frequency of 50 cydes/sec,
and the gases at $<3 \times 10^{6}$ cydes $/ \mathrm{sec}$, except ows indicated.

$$
\begin{aligned}
& \text { (2) } 3 \times 10^{6} \text { cycles } / \mathrm{sec} \\
& \text { (3) } 1 \times 10^{6} \mathrm{cyc} / \mathrm{sec} / \mathrm{sec} \\
& \text { (4) } 3,6 \times 10^{6} \mathrm{cycles} / \mathrm{sec} \\
& \text { (5) } 2 \times 10^{6} \text { cycles } / \mathrm{sec}
\end{aligned}
$$

(c) The dipole moment in electrostatic units (Esu) is for the temperature range indicated.

(d) The physical state of the compounds is for. sea level conditions of $760 \mathrm{mmHG}$ and $25^{\circ} \mathrm{C}$. (e) The probable sources for the trace contaminants are estimates based on deductive chemical reasoning.

(f) This column shows where these trace contaminants were found. The following abbreviations are used.

A - AMRL Chamber (Dayton; 3 men - 30 days) $B$ - BOEING Chamber (Seattle; 5 men - 4 days) $C$ - SAM Chamber (Brooks; 2 men - 30 days) $M$ - MERCuRr spacecraft (Orblt; man - ldap) 5 - Submarines (100 men; 60 days)

(g) The Threshold limit Values ( $T L V$ ) are for intermittent short-term exposures as adapted by the American Conference industrial Hygienists, Aprill 1964.

[ ] Recommended in "Dangerous Propertios of Indestrial Materials" by N.L. Sax, 1963

() Bosed on evaluation of available toricological data 
and the Toxicological Laboratory at Dayton. It is also during this task that most of the specifications for material selection will be written, and that needed research and development programs will be suggested.

It can be expected that the present state of the art will not encompass fully adequate means for ideally implementing some TMCP functions. These problem areas will therefore be considered, and brief descriptions will be written for necessary $R \& D$ programs to determine means of increasing the effectiveness of TMCP designs. The data, including cost estimates, will be presented in sufficient detail to permit NASA evaluation of the effect of the recommended R\&D programs on the implementation of advanced TMCP designs. Some of these programs may be capable of completion in time for TMCP design for the AES. These programs will receive special attention in this task.

A state-of-the-art review in many technological areas of materials control based on toxicological considerations shows that many of the available techniques and methods are inadequate or, at best, ineffecient. Two typical examples of the gaps that must be filled by R\&D work are provided below.

One of the more perplexing problems in inhalation toxicology is related to chemical and/or biological synergism and antagonism among various atmospheric contaminants. These phenomena are virtually impossible to predict from merely a knowledge of the chemicals involved. Carefully designed experimentation is therefore required in order to obtain some insight into this complex problem.

Another problem is recognized in the identification of parameters describing the trace-contaminant generation process. Proper selection of scaling parameters for material tests requires determination of the significance of such parameters as total surface area, surface finish, and cabin volume in addition to environmental variables such as total pressure, temperature, and humidity. 
One of the basic objectives of the work on the material-selection spacification is to develop a series of tests and screening techniques that will (in as few steps as possible) quickly reject or accept materials without requiring exhaustive investigation. Several simple tests (e.g., total weight loss or odor determination) will therefore be chosen so that more complicated and lengthy procedures (e.g., animal inhalation studies) will be used only when necessary.

Physical-chemical specifications and tests offer both disadvantages and advantages. Such tests are generally more easily performed and more reliable than, say, animal experimentation. They have the disadvantage that most such tests are hard to relate to contaminant effects on humans. It nevertheless appears that certain analyses employing the most modern techniques in gas chromatography and thermogravimetry offer possibilities for the detection (at least perhaps by total quantity) of very low concentrations of possible contaminants. It will seldom be possible to devote much time to the individual identification of most trace contaminants, although it may be possible to detect certain functional groups and to classify and quantitate broad categorieş of çmpounds, e.g., chlorinated hydrocarbons.

The end result of this effort will be a series of specifications and related tests written in the precise form required by qualified laboratories. The only type of modification they will require will result from either management or scheduling problems. These will be dealt with later in the program.

\section{Determination of Test Choice and Sequencing}

A relatively short-term effort is required to choose, rank, and sequence each of the various tests. It is important that tests tending to rapidly reject or accept a given material appear first in the sequence. As an example, it would be more efficient to conduct an odordetermination test before attempting a long-term, animal inhalation study. For materials that fail to pass initial screening tests, it is also 
important that more definitive tests be available if some critical-use material has been rejected. Regardless of how carefully limits on the initial screening tests are derived, apparent errors will occur, and the AES project may well decide to check further into the true toxicity of important materials. Depending on the specific types of tests involved, the sequencing may be fairly complex so that the results of one test determine the choice of route through the remainder of the testing plan. Furthermore, the types of materials, equipment, or processes to be tested may influence the sequencing. The test limits, degree of complexity, and completion time will therefore be examined to establish an order of testing that maximizes reliability and efficiency from the standpoint of technical evaluation.

\section{Development of Test Schedules}

Data on the AES mission and space cabin will be reviewed with respect to the specifications and test sequences, in order to determine the cost, manpower, and time requirements for the TMCP. Some idea of the materials, compounds, and equipment to be tested should be available at this point in the program so that loading factors can be determined, and it may become apparent that test-schedule changes are necessary. Loading factors on the TMCP will also influence the requirements for a data pool (see Section IV, B). With the information described in Section IV, C, concerning the AES development cycle and its milestones, more realistic scheduling will be possible and changes may be necessary(in the sequencing and types of specifications). Moreover, the specifications and test schedule can be later closely matched to the development cycle, and the real costs of the TMCP can then be approximated.

\section{B. DATA STTORAGE AND RETRIEVAL}

Adequate data must not only be available but must be easily accessible for the TMCP. A data storage and retrieval mechanism is required that permits ready entry to toxicity data on specified materials and compounds. This section defines some of the input and output requirements of, and constraints on such a data pool and covers aspects of data- 
pool design and development that must be considered in TMCP implementation.

\section{Data-Pool Requirements and Constraints}

In selecting space-cabin materials, the designer's goal, ideally, is to use only materials that do not contribute contaminants to the space-cabin atmosphere. In practice, this goal cannot be achieved and a "go, no-go" decision must ultimately be made for each material on the basis of the best knowledge available - i.e., certain physical, chemical, and toxicological factors. This information may include characteristics such as size, weight, density, state, chemical composition, outgassing products and rates, vapor pressure-temperature relationships, and the toxicity of the outgassing products. The needs of a particular systemdevelopment-cycle schedule as well as the necessary TMCP tests will impose specific requirements on the desired output of the data pool. Because of the limited time available for evaluation of spacecraft materials, the data pool must contain only specifically prescribed and highly relevant data on material toxicity, and therefore cannot be "open-ended" in the usual sense.

The information in the data pool may be collected (a) by screening the vast amount of scattered known information in the chemical, physical, toxicological, and materials literature, and (b) by 1aboratory tests of materials where literature information is not available or is inadequate. The available volume of information, however incomplete, and the possible number of materials, make it clear that experients must be devised to reduce the task to manageable and economical proportions.

The implementation of a data pool will require (a) identification of specific materials data necessary for a toxic-material evaluation, (b) definition of the form in which the data are to be supplied and withdrawn from the data pool, (c) relevant toxicity data, (d) identification of specific materials about which data are needed, and 
(e) a data storage and retrieval facility, including equipment and personnel.

\section{Data-Pool Design and Development}

A readily available pool of retrievable data in useful format will save time and increase the probability that the complete space-cabin system will meet the atmospherérequirements.

The choice of ${ }^{2}$ a manual or a computerized storage and retrieval system will depend to a large extent on the specific information and amounts of data to be handled. The input and output requirements will be defined after the TMCP material-test procedures and schedules have been determined. A manual system may well have a cost-effectiveness advantage because the time required to program a computer might equal or exceed the time required for manual information retrieval.

The order in which data-pool information would be used to evaluate materials depends largely on the availability of physical and toxicological information. The reasonable way to store toxicity information concerning a piece of equipment, for example, would be to file (tere comipment name) data sheets on all the compounds known to be used in $6^{2} e_{1}$ equipment. Data on the individual compounds would also be filed elsewhere. If a piece of equipment had not been investigated and no entry made in the data pool, research work would be necessary. After this research has been done, the data pool could be searched for information by compound names for toxicity information, wer each w". 3--of these names. At this point, an input to the data-storage facility would be made by entering summary sheets on compounds associated with a specific piece of equipment. This type of situation is likely to occur of ten during the operation of the data pool. The original content of the pool 
would be set up on the basis of a list of materials believed most likely to be used in the space cabin under consideration. This prediction would not be entirely successful because of changes in the state of the art and because many companies make different pieces of equipment to perform identical functions, even though the materials of construction are not chemically the same.

The personnel needed for proper operation of a data pool can best be defined after the pool has been designed. $\sigma$ Because the pool will be toxicological monitor will also be required for interpretation and selection of the data to be stored.

Some appreciation of the major development problems may be obtained by considering a likely sequential procedure for the formation of a data pool, as developed below.

\section{A. Step 1}

The first task would be to obtain a list, as complete as possible, of parts and materials for the internal structure of the Mercury, Gemini, and Apollo space cabins, plus any additional data on sopace-cabin simulators, such as those at NASA $X^{\text {Hous ton, }}$, simulators designed by industrial concerns (General Electric, North American, Boeing, Douglas, Republic, etc.) Any relevant information on Soviet space cabins would also be desirable. It is assumed that future closed environments for man, whether for space or underwater use, will be designed with many materials and parts that have been used in the past for etosed environments. The detailed list would establish what compounds, materials, and equipment are most likely to be used in future space cabins and would give the data-pool designer an indication of the magnitude of the task. 


\section{b. Step 2}

In this step, a frequency-of-use table

would be established, with items (broken down by compounds, materials, and equipment) on one coordinate and systems (e.g., Gemini, Apollo) on the other. This would permit identification of the most common items across all systems and provide guidelines or criteria for establishing priorities to be applied to the literature search. It is important that literature pertinent to the equipment expected to be used in space cabins be gathered before design work is initiated.

There is a trade-off point between the cost to gather new data, either by research or literature, after materials have been tentatively selected during design, and the cost in setting up the data pool by gathering information on materials that may or may not be used in the space cabin. The decision-making process can be simplified by employing previous material use experience obtained from the Gemini and Apollo programs. This is extremely critical and should be given the closest attention when attempts are made to determine exactly what should be looked for in the literature.

$$
\text { c. Step } 3
$$

The literature search would be initiated during this phase. It would cover two fronts - physical-chemical and toxicological - and it is believed that time constraints will permit little information to be gathered unless the search for data on candidate compounds, materials, and equipment is begun very soon. If these data are not obtained and entered in the pool early in the development cycle, extensive research on each question which is submitted by the designers is likely to be necessary. An effort is now underway at NASA-Houston to identify the contaminant-production rates for all items being used in the design of the Apollo Command Module. If these data are obtained, it would only be necessary in most cases to determine what research has been done on contaminant toxicity. If 
it develops that these data are not sufficient, research requirements could then be generated and justified. For items with a high probability of use in a system under development, it is hoped that the need for further toxicological research will be recognized early in the design effort.

All relevant toxicological literature should be surveyed and evaluated with regard to the toxicity of compounds, materials, and equipment expected to be used in manned space systems. A list of several hundred major U. S. information sources for toxicological data has been compiled for use in the data-pool survey.

\section{d. Step 4}

In this step the actual searching and evaluation would be performed and the relevant toxicological information would be entered on summary sheets. The major problem will be the magnitude of the task, and will be compounded by the fact that the available toxicological data primarily deal with pure chemical compounds. Most of the data will not be directly applicable to the materials that can be expected to be used in the space cabin. The major sources of information will be (a) previous testing programs for the Gemini and Apollo capsules, and (b) nuclear-submarine design programs. It is also hoped that useful information can be obtained from the manufacturers of components or parts.

$$
\text { e. Step } 5
$$

If much of the necessary information on physical properties were available to facilitate the literature search for relevant toxicological data, a guidance document could be produced for designers that would identify the components likely to generate contaminants beyond an acceptable level of concentration. The guidance document should be produced before the preliminary-design phase of the AES development cycle is initiated. 


\section{f. Step 6}

This would be the last step. Iw would primarily cover the mechanical task of putting the data into an appropriate storage facility.

\section{g. Output}

It is planned that the output from the datapool effort in the proposed study program will define all the requirements for and constraints on the design of a TMCP data pool. The following will be determined: (1) specific requirements to be satisfied by the data pool, (2) specific constraints under which the pool is likely to operate during the TMCP, (3) functions the data pool must perform, (4) data pool content including equipment and personnel, (5) effort involved in, and cost of establishing, such a data pool, and (6) the timetable for an operational data pool.

\section{PROJECT AND PROGRAM MANAGEMENT}

1. Definition of AES Pro ject Organization

The concepts of Configuration Management (see

definitions in Section IV, A, foregoing), as outlined in the Apollo Configuration Management Manual, will be complied with. In addition, the specific nature of the problems involved calls for another level of managerial detail. One of the major problems to be solved in the initiation of an effective TMCP will be establishment of the proper lines of communication. It is expected to be more acute during early phases of the program, when toxicological properties of specific compounds are being gathered rapidly. Much time and effort can be saved and possible retrofits can re avoided only by the rapid collection, correlation, and dissemination of such information. To ensure adequate bookkeeping and accountability for all materials used in space-cabin fabrication, data are required from NASA and all the major contractors performing material-evaluation work. 
The problems to be solved are similiar to those of establishing effective lines of communication in very large, decentralized corporations. The NASA Manned Spacecraft Center, the prime contractor, and the major subcontractors are large organizations with complex structures. Methods will be studied for the expeditious distribution and collection of information, particularly to those who need it in their work. These methods will provide for rapid flow of information to designers and of designers' questions to the TMCP.

It will probably be impossible to reach each designer and working engineer with the TMCP test results. An approach that will be studied is distribution of test results to department heads responsible for the work of the individual designers. These department heads, in turn, will be held responsible for complying with the constraints imposed by the TMCP test results. Techniques of cost-effectiveness analysis will be used to obtain the optimum communication system.

$$
\text { To avoid costly delays and retrofits, effective }
$$
communication policies and procedures must be instituted very early in the program - during the Definition Phase, and hopefully before Design Start.

\section{Definition of AES Development Cycle}

A general layout of the most likely AES development cycle will be prepared. Specific requirements and constraints related to TMCP functions derived from consideration of the cycle will be identified.

Information on the relative schedule for the AES development cycle is needed to specify when TMCP data must be made available and when development-cycle questions will be put to the TMCP. The information gathered will include the identification of major development-cycle milestones: preliminary design, detailed design, and final design. The responsibility with NASA for crew safety and interrelationships with the development cycle will be identified; these will determine 
the types of data desired from the TMCP and the form of presentation. To permit integration with the TMCP the responsibilities of development cycle groups (such as safety engineering, quality-control engineering, and systems engineering) will be determined.

In order to estimate the APS performance and to be able to evaluate the worth of the TMCP in later tasks, advance information will be collected on system-design parameters (e.g., vehicle configuration, volume, design cabin-leak rates, atmosphere composition, pressure, temperature and humidity, and the APS design specification), as well as information on materials and equipment contemplated for use in the AES. Most of this same information is also necessary for the determination of specifications and tests as described in Section IV, A.

The answers to most such questions will be obtained by identifying and contacting the appropriate project groups at the NASA Manned Spacecraft Center and the system-development contractors. When insufficient data are obtained from these sources, engineering estimates will be used to provide supplementary information. A systems engineering approach, employing known or desired start and finish dates and experience in previous spacecraft-development cycles (e.g., Mercury, Gemini, and Apollo), will be used to describe a systems-development cycle. Existing NASA and Department of Defense material specifications will be screened for possible TMCP applicability. Candidate specifications are likely to exist among those already written for environmental and compatibility tests and (to a lesser extent) for contamination and toxicity control.

The TMCP functional requirements will be adjusted or modified to fit the development-cycle requirements and constraints, and the interrelationships of the functions and the development cycle will be described. The questions to be answered in this task include the following: What effect will the time constraints of the development cycle, including major milestones, have on the TMCP, and how can the ideal and unrestrained schedule sequence and data flow, developed on this basis, be modified to fit these constraints? Modifications will be based on the 
inputs obtained from the identification of development-cycle constraints on TMCP functions. Knowledge of the AES development cycle, its goals, and its schedule dates will thus be integrated with TMCP capabilities and requirements.

The system-development-eycle description generated in this task will be used principally in the effort to adjust the basic functional design of a TMCP to fit the AES development cycle (Section IV, C, 4, below).

\section{Determination of Capabilities of Participating Organizations}

It is unlikely that a single toxicological-testing facility will be able to handle all the preliminary and acceptance testing required to ensure the success of AES missions. To maintain schedules at minimum cost, it will undoubtedly be advantageous to distribute various TMCP phases among several qualified toxicological-testing laboratories. Much of the testing will be performed by the TMCP contractor, and many of the preliminary screening tests can probably be carried out by the AES prime contractor or the various subcontractors. In addition, several Government laboratories can substantially aid the TMCP. Before a reasonable assignment of tasks can be made, however, laboratory capabilities and work schedules will have to be evaluated to ensure a reasonable TMCP test program complying with the AES development cycle.

After decisions are made on what tests must be performed (Section IV, A), it will be possible to contact the various candidate laboratories to more completely evaluate their capabilities and work loads. At the completion of this task, a TMCP test schedule can be established that will be realistic and compliant with the overall AES development cycle. 


\section{Determination of Preliminary-Configuration Management Recommendations}

The outputs of various efforts discussed above will be used to synthesize preliminary management recommendations. To some extent these recommendations may be considered to represent the optimum management system because they will not be subject to the constraints of the rest of the TMCP. They will utilize the "base-line" concepts as set forth in the Configuration Management Manua1, with additional management functions as deemed necessary for the program.

The TMCP is primarily concerned with ensuring that the space-cabin environment does not exceed the maximum allowable total level of toxic trace contaminants contributed by its materials of construction. The space-cabin-environment specification and criteria should be established during the Conceptual Phase of the work, which is defined as the period preceding the Definition Phase and terminated by Design Start. The TMCP manager will then be responsible for controlling the sum of the trace contaminants from the materials of construction so that the specified limits are not exceeded.

In the interest of maintaining minimum costs, retrofits for toxicological reasons alone will be avoided unless absolutely necessary. The final decision on retrofitting recommendations will be dictated by the results of cost-effectiveness analyses to determine the optimum choice between the following: (a) probability of mission failure, (b) probability of mission abortion, (c) partial retrofit, (d) complete retrofit, and (e) acceptance of system as it is, but modification of specifications for the next item procured.

All material specifications will be provided in quantitative physical terms with tolerances derived from analytical test or demonstration data. These specifications will clearly state require. ments, not goals. 
Early in the definition phase, all TMCP functions will be described to the level of detail necessary to clearly define the functional interface between, and performance budgets allocated to, the respective functional areas.

In order to comply with the mission requirements, the spacecraft atmosphere must be defined early so that the materialselection specification will be available for incorporation in the Apollo Program Specification during the definition phase.

Because the TMCP is concerned with the total spacecraft environment, it must consider the toxicological properties not only of the components, but also of the subsystems and systems. It will therefore be necessary to establish these requirements before the end of the definition phase when the Project, System, and Contract End Item (Part I) specifications are complete, and the design requirements base line is established.

To ensure compliance with material requirements, it is proposed that the TMCP contractor be represented on the review panel for the proposals submitted in response to hardware procurement requests at the start of the acquisition phase. The purpose is to ensure that system and subsystem contractors are aware of and have considered the toxicological requirements in their proposals.

Adequate justification for including the materialselection-specification as an applicable document may be found in the discussion of human performance, safety and induced environment in Exhibit I of the Configuration Management Manua1. The other exhibits of the Manual will be used as found applicable during the study.

Once the TMCP material-selection specification is included as a "boiler-plate" requirement of the program, project, and system specification, the control of toxic materials will become part of the Configuration Management system. It will undoubtedly be necessary to update these requirements continuously as the test program 
progresses. It will be necessary also to ensure that the following additional steps are taken:(a) the Engineering Change Proposal format will have to be modified to include material-change callouts requiring approval by TMCP personnel, and (b) TMCP representation should be included on the Configuration Control Board.

The output of this task will essentially be a management approach derived from the need for a TMCP within the framework of Configuration Management. This output will serve as input to the final definition of the specification and control program (Section IV, E); during that work the approach will be tempered by constraints imposed by the schedule and the test program in order to arrive at a management system compatible with overall AES program requirements.

D. ASSIGNMENT OF RESPONSIBILITY FOR SPECIFICATIONS, TESTS, AND DATA-POOL FUNCTIONS

With the information obtained in the foregoing work on the capabilities and management aspects of various organizations, it will be possible to assign responsibility for assuring technical compliance with specifications. Responsibilities for other TMCP elements (such as datapool operation) can also be delegated, but at this point in the program such delegations will probably cover a group of organizations rather than one specific organization. It will be possible later in the program to make more specific recommendations. These decisions will eventually represent the optimum choice as influenced by Configuration Management criteria.

Assignment of responsibilities will primarily be based on technical considerations, but scheduling and manpower will also be considered. Responsibility for many aspects of the material-selection process should reside in the TMCP staff, for other aspects in NASA and prime contractors, and for still others in organizations unrelated to either (except that they will perform specific tests in optimum fashion). Tests of a toxicological nature could well fall in the latter category. 
Several choices for various elements of the control program will be submitted to NASA for review so that an unbiased opinion is assured.

In some cases, organizations will be canvassed to determine specific capabilities in a given technical area. It is conceivable that close examination of the facilities, manpower, and scheduling of these organizations may reveal a need for alterations in test procedures, test sequencing, or test scheduling. After responsibilities are assigned, the management techniques and organization can be finalized (as discussed in Section IV, E).

E. FINALIZATION OF TMCP DESIGN

1. Definition of Materlal-Selection Specification and Management Control Program

As shown in Figure 1, the results of all of the previous efforts will be fed into Task 13 to be coordinated into a "program-level" material-selection specification, delineation of effective lines of communication, and the implementation of a Configuration Management Plan.

The key to a successful TMCP is a realistic and usable material-selection specification (MSS) that can be incorforated as a basic part of the AES Program Specification. This MSS will reflect the "safe-air" definition, mission requirements, APS capabilities, and AES development cycle requirements. The availability of an MSS meeting all program constraints will make the basic desıgn of the TMCP a problem of conforming to the NASA Apollo Configuration Management Manual.

It is necessary to consider schedule constraints in order to establish a meaningful program, because an extremely large number of toxicologically oriented tests of varying complexity may be necessary, some requiring long periods of time. The more time available for toxicological testing, the higher the probability of a successful 
mission. It is therefore vitally important to the program to define "safe-air" and prepare the MSS as early as possible; the amount of testing that can be accomplished will be determined by the amount of time remaining in various elements of the development cycle.

Comparisons of cost and effectiveness must be available to permit evaluation of the worth of a given TMCP. In this portion of the program, the cost of implementing a TMCP design and possibly several alternative designs) will be estimated. Cost estimates will be presented in terms of the number and types of personnel needed and facilities required for implementation of each candidate program.

The candidate TMCPs that will be compared must be useful for the AES. To meet this requirement, any necessary or desired TMCP research and development work must be completed before the finalsystem design is initiated. The costs associated with each candidate program as defined in this task will however, be based only on the costs needed for program implementation.

This cost information will be used in conjunction with an estimate of effectıveness for an informal trade-off analysis that will yield a recommended final "preliminary" TMCP design implemetable in time for the AES. The information will include personnel and facility requirements for each TMCP preliminary design, as well as the systemdevelopment-cycle constraints (particularly those of the required interrelation between the TMCP and the development cycle), and the time constraints on TMCP implementation.

It is hoped that all program constraints will be available early enough to assure that a simple, yet effective management control program can be instituted. In addition, it must be recognized that the probability of successful missions will also be a function of a successful TMCP. The entire AES Program will therefore have to be constrained, to some extent, by the TMCP. The earlier tasks were in the main, directed toward obtaining precise definitions of these constraints. 
The task described here represents an effort to refine and finalize all suggested methods of control.

2. Establishment of Management Responsibility and Organization

The technical information on, and preliminary assignment of responsibilities for, specifications and testing will be examined with respect to the AES development cycle and organization in this task. The work will permit the modification of basic configuration management techniques for the purpose of assigning final responsibility for management aspects of the TMCP organization. In addition, decisions on specific functions of material selection will be made; an example is discussed below.

For a specific material, piece of equipment, or process, TMCP functions terminate in a decision to act in one of several different ways. The decision can not be made solely on the basis of toxicological information but requires engineering information from the system development cycle. As an example, it will occasionally be necessary to use a toxic material and thus impose a specified load on the onboard APS simply because no engineering solution permits the use of a nontoxic material.

Because engineering data that will not be available to the TMCP are required in this final decision, the question arises: Where should responsibility for the final decision reside (e.g., within the TMCP or the system-development program office)? This question is best answered by systematically identifying the kinds of information needed for the final decision. Typical questions that may be put to the TMCP will have to be considered in order to determine what information must be presented to this final-decision function. The manner in which the TMCP must articulate with the system-development cycle can then be determined.

Such determinations exemplify elements of organization, and eventually management, that must be developed before a TMCP 
becomes useful.

In the effort directed toward recommending a satisfactory organization, the proposed study will consider several alternative structures. The final recommendations will be made after a cost-effectiveness analysis of these alternatives.

This cost-effectiveness analysis, coupled with the same sort of effort in the preceding task (IV, E, 1), will provide bases for the necessary decisions on the organization of the TMCP. It remains then to apply configuration management techniques to the detailed organization plan to facilitate final decisions on responsibilities and work loads.

Not only must costs and schedules associated with the material-selection specification be delineated, but the proposed program must assure that proper liaison and open-end communications are maintained which feature simplicity and flexibility. The latter is impor. tant because schedule constraints necessitate rapid and orderly collection and dissemination of the results of evaluations and testing. The effort is thus one that the technical and management aspects of a TMCP combines into a finalized statement of how and when materials selection is made from a toxicological standpoint.

\section{Preparation of Final Report}

A final report will be prepared that covers all outputs of the individual tasks of the study program. It will incorporate a Materials Selection Specification, based on toxicological considerations, that can be used in prime-contract and subcontract schedules, and will present a detailed plan for the management of a Toxic Materials Control Program to assure adherence to all elements of the specification. The report will also include Aerojet's recommended assignment of responsibilities, estimated costs, and manpower and facility requirements. In addition, technical areas that require research and development effort will be described and suggested R\&D programs will be outlined. 


\section{STUDY PROGRAM PLAN}

Aerojet proposes a 15-task program extending over a period of 25 weeks as depicted in Figure 1. The task descriptions follow the order of the sub-sections and are reflected in the technical approach as discussed in Section IV, foregoing. Figure 1 also indicates the interfaces and necessary inputs to the sequence of tasks which are represented by bars. Arrows indicate the direction of data flow.

This program will be accomplished expeditiously under the management of Dr. M. Y. Longley by the experienced team of engineers and scientists described in Section VI, following. 
VI. CAPABILITIES

\section{A. APPLICABLE EXPERIENCE}

The evaluation and control of space-cabin atmospheres constitute a major interest of Aerojet's Life Support Systems Division. Areas in which the division has worked include determination of unknown gaseous and particulate contaminants of space-cabin atmospheres and unusual industrial environments, industrial-hygiene aspects and toxicology of missile propellants and other materials associated with the aerospace industry, development of specialized research facilities and basic research in inhalation toxicology, and development of new techniques in trace-gas analysis.

The division has acquired experience in depth in the systems approach to the solution of complex problems through close collaboration with the various Aerojet plants in aerospace efforts. This approach was applied throughout its just-completed study of integrated waste-management systems for the State of California under contract No. 347. That investigation considered the whole problem as a single system in order to reveal opportunities for the integration of existing elements for more effective and economical management of all types of wastes.

Under Aerojet's Independent Research and Development (IR\&D) Program, the division is actively engaged in investigation of the control of toxic contamination in enclosed atmospheres. Especially pertinent here is a study of the control of trace-contaminant sources in which attempts are being made to determine contaminant-production rates for a wide range of sources as well as toxic effects during continuous long-duration exposures. This work involves ( 1 ) determination of design criteria for and concepts of a toxicological data pool for the evaluation and selection of spacecraft materials and equipment, (2) development of a theory for employing shortduration and intermittent-exposure toxicological data for the prediction of toxicological effects of continuous long-duration exposures, (3) determination 
of procedures for rapid qualitative and quantitative analysis of trace contaminants in space-capsule simulators, and (4) investigation of the feasibility of simulating trace-contaminant generation sources, rates, and patterns.

Also pertinent is the division's specific experience in the development of animal-inhalation exposure facilities. Aerojet designed, built, and is operating an inhalation toxicology facility for the Aerospace Medical Research Laboratories (AMRL) at Wright-Patterson Air Force Base (WPAFB) under Contract AF 33(657)-11305. The most recent addition to this contract involves the design and fabrication of a special facility for study of the toxicology of offgassing products from materials to be used in the Apollo cabin. The experimental work associated with this program embodies many new concepts and techniques in inhalation toxicology.

Aerojet's related experience is summarized in the tabulation

below.

Company-sponsored

Contract AF 33 (657)11305 with USAF-AMRL, WPAFB

Contract AF 41(609)-2783 with USAF-SAM, Brooks AFB, Texas

Contract AF 33(616)-7836 with USAF-AMRL, WPAFB
Control of toxic contamination of enclosed atmospheres, 1964 - present

Research and development work on and operation of the Toxic Hazard Research Unit at Wright-Patterson AFB, 1963 present

Analysis of trace contaminants from a closed environment system, initiated 1965

Study of the toxic hazards of selected missile propellants, 1961 - 1962 
Contract AF 33(657)-10951 with USAF-AMRL, WPAFB

Contract AF 33(615)-2926 with

USAF-AMRL, WPAFB

Contract AF 33(657)-10538 with

USAF-AMRL, WPAFB

Contract DA-04-495-AMC-255(Z)

ARPA - Army Missile Command

Contract AF 33(600)-35789 with

USAF-ASD, WPAFB

Contract AF 04(611)-7441 with

USAF-AFRPL, Edwards AFB

Contract AF 49(638)-857 with

USAF-OSR, Washington, D. C.

Contract Nonr 2655(00) with

USN-ONR, Washington, D. C.

P.0. N-35238 with

NASA-JPL, Pasadena, California

Contract NAS 7225 with

NASA-OART, Washington, D. C.
Evaluation of the toxic hazards of selected missile propellants, $1963-1965$

Study of the toxic hazards of selected missile propellants, initiated 1965

Study of the pharmacological mechanisms of action of difluoramino compounds, $1962-1963$

Evaluation of high energy material as liquid propellants, 1964

Boron hydrides in air, analysis systems $1959-1960$

Corrosive fluorine oxidizer analysis $1963-1964$

Decomposition studies, 1963 - 1964

Nitrogen-oxygen-fluorine, compound analysis, 1954 - present Lunar chromatograph surveyor package $1960-1961$

CO reduction, $1962-1965$ 


\section{B. FACILITIES}

Aerojet-General is heavily engaged in the development and manufacture of propulsion systems. Its facilities are numerous and its experience extensive in the development and handling of hazardous chemicals and in testing operations involving hazardous chemicals. Because the proposed study program requires only a few of these facilities, no attempt will be made to describe all of Aerojet's capabilities in this regard. In summary, however, Aerojet's Von Karman Center (VKC) has constructed some 50 buildings and 48 test bays for testing activities. They include many special test systems, completely equipped laboratories, service facilities, and office space, and the total value of the VKC test installation is approximately $\$ 5,000,000$.

To facilitate communication among personnel assigned to the proposed study, a special, unencumbered work area will be made available for the investigation. Other VKC facilities pertinent to this and possible future programs are described below.

\section{Life Support Systems Division}

This division employs the combined talents of personne 1 in the biological and physical sciences in evaluating and improving many aspects of man's environment. The division has technical personnel experienced in the fields of occupational medicine, industrial hygiene, toxicology, genetics, physiology, biophysics, bacteriology, thermodynamics, mechanical engineering, aeronautical engineering, operations research, statistics, and reliability.

In support of its technical staff, the division maintains wel1 equipped biochemistry, toxicology, pharamocology, and microbiology laboratories. The toxicology facilities and staff are located at the VKC and at Dayton, Ohio; both laboratories are uniquely equipped to handle various inhalation-exposure experiments. Within the VKC, housing space is available for approximately 2000 mice, 400 rats, 130 guinea pigs, and 30 rabbits or cats, or their equivalents. 
The division's Laboratory of Biological Sciences is accommodated in two buildings each having $1000 \mathrm{sq} f t$ ff floor space. It contains (a) animal food and waste bins, water bottles, and scales, (b) holders for experimental animals, (c) inhalation-exposure equipment, (d) smooth muscle bath facilities and recording equipment, (e) hematology equipment and materials for blood-cell studies, (f) mixing equipment and materials for pharmaceutical suspensions, ( $g$ ) drug supplies for asesthesia and anticoagulant use, (h) a wide variety of standard laboratory reagents, (i) surgical instruments, ( $j$ ) compressed-gas regulating equipment and a variety of flowmeters, (k) analytical balances, ( 1 ) constant-temperature baths, (m) metering infusion pumps, ( $n$ ) refrigerator and deep-freezer facilities, (o) drying ovens, (p) numerous chemical hoods, (q) kymograph and oscillographs, ( $r$ ) distilled-water facilities, and (s) standard laboratory glassware.

Supporting laboratories in the division are equipped with other standard items, including an autoclave, $\mathrm{pH}$ meters, incubators, research microscopes, spectrophotometer, gas chromatograph (set up to analyze $\mathrm{CO}, \mathrm{CO}_{2}$, and $\mathrm{O}_{2}$, plus a loop for standard gas chromatographic procedures, Warburg apparatus, micro-Kjeldahl unit, continuous-flow paper electrophoresis, Sorvall refrigerated high-speed centrifuge, and ultraviolet sources, in addition to culture vesse1s, pumps, flowmeters, and other equipment necessary for culturing microorganisms. Facilities for handling highly toxic and shock-sensitive materials are also available.

Aerojet has constructed one of the most advanced animalexposure systems in the nation. In essence, it consists of an air purification and compression assembly, toxin generators (or compressed-gas cylinders), mixing units, and three modular exposure units, each of which contains 12-1iter glass-Teflon exposure chambers. The air purification and compression assembly consists of an "absolute" intake particulate filter, a Nash rotary air compressor capable of delivering $20 \stackrel{\mathrm{f}}{\mathrm{fm}}$ of air at $82 \mathrm{psig}$, a dehumidifying system, two activated-charcoal beds arranged in parallel and capable of operating 
separately for regeneration purposes, a millipore filter capable of removing particulates of less than 1 micron diameter, a storage tank, cylinders of bottled air for emergency purposes, and appropriate controls for the system.

The Nash generator is a water-seal rotary compressor through which 5 gallons of water flow per minute. It serves to water-scrub the air in addition to performing a sealing function. Air is piped to mixing stations on each modular rack and the air, plus toxic gas, is pumped into individual chambers. Flow rates are controlled by the use of critical-pressure orifices and are monitored by Rotometer flowmeters. The use of glass and Teflon chambers and distribution tubes prevents possible test-substance reactions catalyzed by metals. The surfaces are inert to all substances except certain fluoride compounds and molten alkalis. The chambers are 12 by 15-in. Pyrex bell jars. Quick-acting toggle clamps are used to seal the chamber closures. Each chamber requires less than 2 minutes per week of down time for cleaning.

The following special equipment is available for analytical and supporting studies: (a) a Loe dual-column gas chromatograph and Brown millivolt strip recorder equipped with a disk integrater device, (b) Astrup physiological blood-gas analysis apparatus, (c) Offner eight-channel ink-recorder system including a type DMR amplifier system and type 503 mobile console, with assorted pressure probes, (d) MSA Type DF 77600 oxygen indicator, and (e) Thermoco Model P2 carbon dioxide analyzer.

In addition, the usual toxicological laboratory equipment and facilities are available.

The division's Microbiology Laboratory is equipped for research studies in the general area of microbial physiology. Continuousculture methods based on the operation of a Chemostat have been used extensively, especially in connection with waste-management problems. The bio- 
logical recovery of water from urine is another area of application. This work extends into a basic study on the interaction of mixed populations of microorganisms in continuous culture. Other areas of interest are related to microorganisms able to survive in seemingly hostile and unusual environments. Sulfate-reducing bacteria, halophiles from desert lakes, and marine organisms have all been studied in this 1 aboratory.

\section{Chemical and Structural Products Division}

This division has the following departments: Applications Research and Development, Chemicals, Instrumentation and Analysis, Water Resources, Fuels and Combustion Research, Composite Structures, Glass Technology, and Program Management.

The facilities of the analytical section are centralized in one 6700-sq-ft building devoted exclusively to its activities. This modern structure consists of 21 laboratory and office units containing modern scientific equipment valued at nearly $\$ 500,000$. Approximately $5300 \mathrm{sq}$ ft of the total area is devoted to the development of new analytical methods and the pursuit of specific research. A $1400-s q-f t$ laboratory wing is used for test and acceptance analysis, as well as statistical evaluation of department-developed methodology. More than 500 standardized analytical procedures are employed in support of other departments, including the receipt and inspection of raw materials. A gas-analysis facility is grouped to include 16 assorted special-function gas chromatographs, reflecting the latest development in detection devices. A recent-model mass spectrometer (CEC Mode1 21-130) for high-vacuum systems completes this facility. A microanalytical laboratory is in continuous operation. In addition to the classical Dumas and Pregel-Unterzaucher combustion apparatus, this group operates micro-versions of apparatus for the Clark-Zeisel alkoxy, the Wickbold fluoride, and the Karl Fischer procedures. Equipment is also available for physical-property measurements, as is a fully equipped glass-blowing facility for the fabrica- 
tion of special aparatus.

\section{Corporate Technical Library}

Data accumulated over a long period are readily available to project personnel through Aerojet's Corporate Technical Information Center (CTIC) files and library facilities. The in-house availability of such data is a matter of great importance to the successful and expeditious completion of this study and the resulting management of a TMCP.

To meet the need for complete technical information service at the VKC, Aerojet maintains a technical library staffed by two professionals, three subprofessionals, and eight office and technical personnel. Mrs. M. T. Grenier, corporate librarian, is responsible for its operation as well as for the operation of the CTIC, which has an additional staff of five, including two abstractor indexers.

These facilities emphasize biology, chemistry, physics, and other sciences related to space research. They acquire needed material rapidly, either on a permanent basis or by loan, and acquisitions are publicized in a biweekly list. The specific interests of individuals are served by automatic distribution of pertinent abstracts on a monthly basis.

The library holdings include 12,000 technical books, 100,000 technical documents, 1150 bound journals, and current subscriptions for 950 titles. To augment this collection, the twice-weekly Pacific Aerospace Library listing of current periodical articles is circulated. In addition, the latest copies of Current Contents in (a) the chemical, pharmacomedical, and life sciences fields and (b) the space, electronic, and physical sciences areas are kept in the library, making available knowledge of the latest publications in a wide span of peripheral sciences. 
Abstract and index collections that open the way to many more publications are available. They include Chemical Abstracts, Biological Abstracts, DDC(ASTIA) Technical Abstract Bulletin, the NASA Scientific and Technical Aerospace Abstracts, Nuclear Science Abstracts, Chemical Propulsion Abstracts, (published by the Chemical Propulsion Information Agency), Technical Translations, Applied Science and Technology Review, Engineering Index, Applied Mechanics Reviews, and ASM Review of Metal Literature.

Close working relationships are fostered and maintained with all major libraries in the Southern California area, including libraries at the Stuart Company, City of Hope, Los Angeles County Medical Association, University of Southern California, University of California at Los Angeles, and University of California at Riverside, as well as the Los Angeles Public Library, the Honnold Library at the Clarement Colleges, and various other libraries. Loans are requested from all over the world; many items are furnished by the Linda Hall Library, the John Crerar Library, the Library of Congress, and the Midwest Inter-Library Center, as well as such defenseoriented sources as Brooks Air Force Base, San Antonio, Texas.

The CTIC indexes in depth (using Jonker's Termatrex equipment) all technical documents acquired, as well as Aerojet-produced technical reports. The Aerojet Library at the Sacramento Plant provides access to its extensive collection through the IBM 7094 computer indexing system. In addition, completely updated duplicates of the magnetic-tape reels produced by NASA can be searched for all NASA holdings through that computer service.

Competent, qualified people search the literature either on-site or at any of the local libraries. Results are furnished as requested in a bibliography, as a literature search, or as a state-of-the-art document. 


\section{Computing Sciences Division}

The Analytical Sciences Department staff and equipment represent the most up to date in analog and digital technology. The department is concerned with mathematical-model formulation and simulation, evaluation and development of analytical and computing methods for various types of computing equipment, and recommendation of appropriate computing methods for programing and mechanization. The equipment available at the VKC includes digital-computer facilities with the IBM 7094, Mode1 2 and its peripheral equipment; a Hybrid Computer Facility that includes a generalpurpose digital computer, analog computers, and a linkage system; and analogcomputer facilities with differential network and thermal analyzers and a dynamic simulator. The Computing Sciences Division will program and operate the IBM 7094 computer for the proposed program as necessary.

C. ORGANIZATION AND PERSONNEL

A project group will be organized specifically for this multiplediscipline program with its highly interdependet tasks.

I. M. Roberts, as Project Engineer, will be responsible for scheduling, assignment of tasks to task leaders, continuous control of costs, and accomplishment of work according to schedule. He will also be directly responsible for tasks dealing with configuration management techniques and system development-cycle integration, and for the preparation of all reports and briefings.

This arrangement will permit Dr. M. Y. Longley, Manager, Environmental Analysis and Control, to manage the program and to apply his technical skills in indistrial hygiene and toxicology without diluting his efforts in the daily exercise of project control. He will report directly to Dr. B. D. Culver, Manager, Life Support Systems Division, on a biweekly basis. Drs. Longley and Culver will thus monitor all technical aspects of the program. The staff directly assigned to the program will also have the assistance of an advisory panel of technical experts available at the Von Karman Center. 
Brief biographical resumes are presented below for key personnel and consultants. As noted, they are highly skilled in toxicology, environmental medicine, materials engineering, management techniques, analytical chemistry, physics, data processing and storage, biostatistics, and thermodynamics.

\section{Key Personnel}

- B. D. CULVER - BS (Biology), Stanford University; MD, Stanford University; MS (Occupational Medicine), University of Rochester, Ten years of experience in occupational, industrial, and aerospace medicine. Studies of insecticide exposures and research on the effects of various environments on workers. Medical Director at Aerojet's Von Karman Center. Manager, Life Support Systems Division and responsible for the development, installation, and operation of the Toxic Hazards Research Unit in the Aerospace Medical Research Laboratories at Wright-Patterson Air Force Base, Ohio.

\section{Y. LONGLEY - BA (Chemistry and Bacteriology),}

University of Iowa; $\mathrm{PhD}$ (Preventive Medicine and Industrial Hygiene), University of Iowa. Eight years of experience in industrial hygiene and toxicology. Research and instruction in preventive medicine and toxicology. Environmental field studies and basic research on aerosol analyzers, electromagnetic radiations, and human factors. Presently Manager, Environmental Analysis and Control for the Life Support Systems Division, and responsible for work on industrial hygiene aspects of propellants and evaluation of closed-environment contaminants. 
I. M. ROBERTS - BA and MA (Chemistry), Brooklyn

College; MBE (Business Economics), Cilaremont Graduate School. More than 7 years with Aerojet-General, including 2 1/2 in engineering administration and program management. Total of 9 years in 1iquid - and solid-propellant chemistry, including preparation and handling of high-energy and toxic materials on laboratory and pilot-plant scales. Additional work in the field of detergents, specialty chemicals, and polymers. Presently assigned to chemical and management problems in the Life Support Systems Division.

\section{D. HUBER - BS (Mechanical Engineering), Case}

Instutute of Technology; graduate studiesin heat transfer and thermodynamics, and advanced work in engineering at Case Institute of Technology and the University of California at Los Angeles. Seven years of experience in the aerospace industry. Design of zero-g boiling and condensing experiments, and basic research on two-phase flow phenomena. Analysis and design of space radiator-condenser systems, and thermal analysis of rotating machinery for space power systems. Analysis of thermodynamic and heattransfer problems in attitude-control rockets. Analysis, research, and development work on environmental control systems, including control of trace contaminants and their sources.

T. P. JACKSON - BS (Mechanical Engineering) Kansas State University; MS (Engineering), University of California at Los Angeles. More than 10 years Aerospace experience, including aerothermodynamic analysés, of various types of rocket vehicles and aircraft. Has directed the analysis, design, and development of a series of passive temperature-control systems for earth satellites. Currently managing product development in the Life Support Systems Division, where he is involved in all aspects of research and development work on air-purification systems. His input to the proposed program will be in this are a and in consideration of thermal factors involved in the generation of trace contaminants. 


$$
\text { E.C. GRIESEMER - BS (Biology), Loyola University of }
$$

Chicago; MS (Pharmacology), Loyola; $\mathrm{PhD}$ (Pharmacology), Northwestern University. Twelve years of experience in toxicology, pharmacology, and biochemistry. Instruction and research in pharmacology. Evaluation of missile compounds and related compounds. Toxicological studies and techniques for extrapolation from short-duration, intermittent exposure to long-duration, continuous exposure to toxic environments.

$$
\text { F. H. CASSIDY - BS (ChE) Gonzaga University. Fourteen }
$$

years of experience at Aerojet-General in the development and utilization of nonmetallic materials. Preparation of material specifications for Aerospace programs. Current responsibilities in corrosion research, electroplating, vapor plating and preparation of specifications for SNAP-8. Past experience mainly in directing the utilization of plastics, elastomers, lubricants, and ceramics.

J. D. MacEWEN - BS (Chemistry), Wayne University; MS (Industrial Hygiene), University of Michigan; PhD (Physiology and Pharmacology), Wayne University, Ten years of experience in toxicology and industrial hygiene; nationally recognized industrial toxicologist. Developed an Air Force inhalation-toxicology laboratory for investigation of industrial and space-cabin atmospheric contaminants. Assistant professor of industrial medicine and hygiene prior to joining Aerojet's Life Support Systems Division. Air Force consultant in toxicology and pharmacology. Currently Laboratory Director, Toxic Hazard Research Unit, Dayton, Ohio.

\section{S.S. BERG - BS (Physics), San Diego State College;}

MS (Physics), University of Washington; PhD (Engineering Physics), Cornell University. Seven years of experience in nuclear engineering and physics. Direction of experiments with nuclear reactors and design of experiments to study fission products in nuclear rocket-engine exhaust. Analysis of plasma jet experiments for re-entry studies, detonation and atmospheric-diffusion studies. Vibration analysis on a biological centrifuge, and development of design requirements for a thermesthesic sensor. Theoretical investigation of cardiovascular fluid dynamics and methods of simulating cardiac stroke output. Analytical and experimental analysis of outgassing products from materials. 
R. M. ROBERTS - BS (Chemistry), University of California at Los Angeles. For the past 7 years, organization and data review for analytical problems ranging from derivation of statistical control parameters in solid-propellant mixing, to development of criteria for acceptability of potable water procured from distilled urine. Project engineer for propellantcontaminant-analyzer program, and chief investigator for a study of new means for analyzing toxic contaminants in closed systems. Currently supervisor of instrumental analysis in Aerojet's Analytical Chemistry Department. Will serve the proposed program as an expert on up-to-date analytical test procedures.

M. T. GRENIER, BS University of Wisconsin; BS Library Science, University of Southern California. Sixteen years of experience in establishing library procedures and document-control and indexing techniques. Initiated a "deep-indexing" system for technical reports, including a Uniterm card system for indexing incoming documents. Responsible for computer-programing of Aerojet technical-document files, and instrumental in formulating the Corporate Technical Information Center. Advisor to and officer in several documentation institutes and library associations. Currently, Aerojet Corporate Librarian responsible for all technical-data storage and retrieval systems within the corporation.

\section{R. A. MARTIN - BS (Business Administration), Colorado}

University and San Diego State College. Specialist advising projects within Aerojet-General on all aspects of Configuration Management, including cost estimates and establishment of $\mathrm{CM}$ systems in accordance with the requirements of AFSCM 375-1. Previously Head, Specifications and Standards for SNAP-8 and Senior Specifications Engineer for an orbiting-sensor program. Formerly with General Dynamics, San Diego in Specifications and Standards Group and as Vice President and Treasurer of a technical documentation company which he. was instrumental in forming. 
R. D. FARQUHAR - BS (Chemistry), Illinois College and extensive training in advanced mathematics, probability, and statistics at University of California at Los Angeles. Statistical consultant for numerous engineering and biomedical programs. Instrumental in developing experimental designs and statistical evaluations for Life Support Systems Division research programs. He will serve the proposed program in this capacity and will also be available for consultation on applications of sampling methods, statistical quality-control techniques, and systems analysis.

\section{Consultants}

The consulting services of Drs. H. C. Hodge and D. Flickinger will also be available to the proposed program.

H. C. HODGE - BS, University of Illinois; MS, State University of Iowa; PhD (pharmacology), State University of Iowa. Has gained world-wide recognition in toxicology. Serves on a number of toxicology committees and as consultant to many Government and industrial organizations; currently retained by Aerojet-General in this capacity. Author of more than 200 scientific papers and books in the field. Current interests include closed-system atmospheric contamination. Will advise Aerojet's toxicologists on a scheduled basis for this program.

D. FLICKENGER - $\mathrm{AB}$ and $\mathrm{MD}$, Stanford University. Brigadier-General USAF Ret., a noted authority in aerospace medicine and bioastronautics for some 20 years. Most recently Director, Life Sciences and Bioastronautics, Andrews Air Force Base. Now serving as a consultant to NASA, the Department of Defense, and industrial organizations, including Aerojet-General. Holder of many awards, and specialist in the areas of stress and fatigure andvasomotor control mechanisms as affected by anoxia, hypoxia, and temperature extremes, as well as a wide range of psychological disorders of flying, bioengineering problems, and space-. craft-system development. He will be available to this program on an oncall basis. 


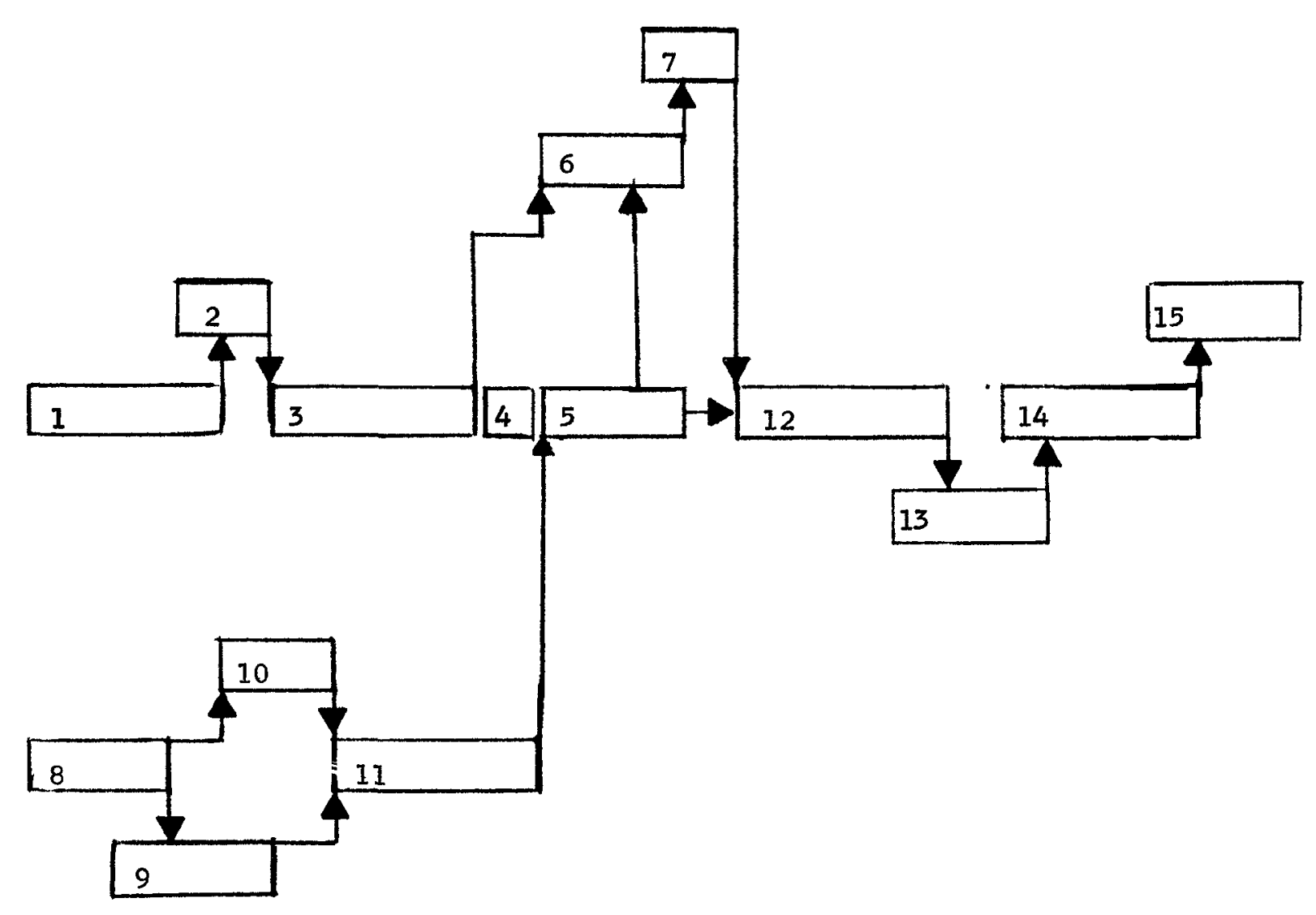

STUDY PROGRAM PLAN

\section{Task Descriptors}

1. Safe Air Defined

2. Spec \& test criteria developed

3. Test procedures determined

4. Test sequence determined

5. Test schedules developed

6. Data Pool inputs and outputs determined

7. Data Pool personnel and equipment determined

8. AES project organization defined

9. AES development cycle defined

10. Capability of participating organizations determined

11. Preliminary Configuration Management. recomendations generated

12. Responsibility for specs, tests and daţa pool functions assigned.

13. Materials selection spec \& management control program defined

14. Management responsibility and organization established

15. Final Report (including research suggestions) written 